\title{
Methanol and Formaldehyde Oxidation by an Autotrophic Nitrifying Bacterium
}

\author{
By PHILIP A. VOYSEY† AND PAUL M. WOOD* \\ Department of Biochemistry, University of Bristol, Bristol BS8 1TD, UK
}

(Received 30 May 1986; revised 30 September 1986)

\begin{abstract}
The products of incubation of Nitrosomonas europaea with methanol were studied by ${ }^{13} \mathrm{C}$ NMR spectroscopy. The methanol was converted into formaldehyde, which was at least partially oxidized to formate. Methanol oxidation was prevented by inhibitors of the ammonia oxidizing enzyme, ammonia monooxygenase. The effects of hydrazine and $\mathrm{NH}_{4}^{+}$were as found in earlier studies with other substrates for ammonia monooxygenase. From experiments in which ammonia and methanol were simultaneously oxidized, the specificity parameter $k_{\text {cat }} / K_{\mathrm{m}}$ was 0.008 for methanol, relative to unity for uncharged ammonia. The rate of growth was not enhanced by methanol, and attempts to grow the cells with methanol as energy source were unsuccessful. Formaldehyde proved much more toxic than methanol when added to shake-flask cultures. Hydroxylamine, an intermediate in ammonia oxidation, reacts with formaldehyde to form formaldoxime. Formaldoxime inhibited hydroxylamine oxidation, providing a specific mechanism for formaldehyde toxicity.
\end{abstract}

\section{INTRODUCTION}

The biological oxidation of ammonia is predominantly brought about by autotrophic bacteria, typified by Nitrosomonas europaea. These nitrifying bacteria have an obligate dependence on $\mathrm{CO}_{2}$ as major carbon source, and only a very limited ability to make use of organic carbon (Krümmel \& Harms, 1982; Martiny \& Koops, 1982). Nevertheless, Jones \& Morita (1983) found that nine different strains were all able to incorporate carbon from labelled methane. The strains were also all capable of the complete oxidation of methane to $\mathrm{CO}_{2}$. Attempts to grow the cells with methane as an energy source proved unsuccessful.

The primary reaction of ammonia oxidation is a hydroxylation, brought about by ammonia monooxygenase (Wood, 1986).

$$
\mathrm{NH}_{3}+\mathrm{O}_{2}+2[\mathrm{H}] \rightarrow \mathrm{NH}_{2} \mathrm{OH}+\mathrm{H}_{2} \mathrm{O}
$$

This enzyme is also capable of using a wide range of organic substrates including $\mathrm{CO}$, ethylene and phenol (Tsang \& Suzuki, 1982; Hyman \& Wood, 1984; Hyman et al., 1985). Hyman \& Wood (1983) showed that methane oxidation to methanol by $N$. europaea was sensitive to the same inhibitors as ammonia oxidation, and had other properties implying that ammonia monooxygenase was responsible.

The present study explores the further metabolism of methanol by N. europaea, which has not previously been investigated. Among other techniques we have used ${ }^{13} \mathrm{C} N \mathrm{NMR}$, shown to be very informative for $C_{1}$ research by Cornish et al. (1984) and Hunter et al. (1984). Formaldehyde tends to form addition compounds by reversible reactions. These adducts might react as free formaldehyde in chemical determinations, or might not be detected. Such uncertainties are avoided by ${ }^{13} \mathrm{C} \mathrm{NMR}$, which enables the species actually present to be identified.

† Present address: Flour Milling \& Baking Research Association, Chorleywood, Herts WD3 5SH, UK. 


\section{METHODS}

Growth of the organism. Nitrosomonas europaea ATCC 19178 was kindly supplied by Dr N. Walker (Rothamsted Experimental Station, Herts, UK). For most experiments the cells were grown in semi-batch culture (Shears \& Wood, 1986). The cells were also grown in shake-flask batch culture, using 21 flasks containing 11 of the following medium: $14 \mathrm{mM}-\left(\mathrm{NH}_{4}\right)_{2} \mathrm{SO}_{4}, 3 \mathrm{mM}-\mathrm{KH}_{2} \mathrm{PO}_{4}, 0.75 \mathrm{~mm}-\mathrm{MgSO}_{4} .7 \mathrm{H}_{2} \mathrm{O}, 0.2 \mathrm{~mm}-\mathrm{CaCl}_{2} .2 \mathrm{H}_{2} \mathrm{O}, 10 \mu \mathrm{M}-\mathrm{EDTA}, 6 \mu \mathrm{M}-$ $\mathrm{FeSO}_{4} \cdot 7 \mathrm{H}_{2} \mathrm{O}$ and $1 \mu \mathrm{M}-\mathrm{CuSO}_{4} .5 \mathrm{H}_{2} \mathrm{O}$. Immediately before inoculation the $\mathrm{pH}$ was adjusted to 7.7 with sterile $5 \%$ (w/v) $\mathrm{Na}_{2} \mathrm{CO}_{3}$, and the $\mathrm{pH}$ buffering was increased by adding $50 \mathrm{~mm}$-phosphate from a sterile stock of $\mathrm{K}_{2} \mathrm{HPO}_{4} \cdot 3 \mathrm{H}_{2} \mathrm{O}$ and $\mathrm{NaH}_{2} \mathrm{PO}_{4} \cdot 2 \mathrm{H}_{2} \mathrm{O}$ in a $10: 1$ (w/v) ratio. A $10 \mathrm{ml}$ inoculum was then added aseptically. Growth was monitored by determining nitrite spectroscopically, assuming $\Delta \varepsilon(335 \mathrm{~nm}-400 \mathrm{~nm})=0.0225 \mathrm{~mm}^{-1} \mathrm{~cm}^{-1}$ (Strickler \& Kasha, 1963).

Testing for contaminants. Cultures were regularly tested for heterotrophic contaminants by using nutrient agar plates. The number of colonies was counted after $5 \mathrm{~d}$ incubation at room temperture. In shake-flask cultures contamination was rarely found, and any contaminated flask was discarded. In semi-batch culture the contaminants generally rose to about $1 \times 10^{6}$ to $5 \times 10^{6}$ c.f.u. $\mathrm{ml}^{-1}$ during the first 2 weeks, and remained roughly constant thereafter. The population of $N$. europaea at harvesting could be estimated as $2 \times 10^{8}$ to $3 \times 10^{8}$ cells $\mathrm{ml}^{-1}$, according to literature values for a similar dry weight per litre (Drozd, 1976; Jones \& Morita, 1983). The contamination would therefore have been about $1 \%$ of the total cells. Critical experiments were repeated with uncontaminated cells from shake-flasks, without any change in behaviour being found.

Preparation of cells for experiments. Cells were harvested by centrifugation at $4{ }^{\circ} \mathrm{C}(28000 \mathrm{~g}, 30 \mathrm{~min})$, and were washed in $40 \mathrm{mM}$-potassium phosphate buffer, pH 7.5, plus $2 \mathrm{mM}-\mathrm{MgCl}_{2}$ and $0.15 \mathrm{mM}-\left(\mathrm{NH}_{4}\right)_{2} \mathrm{SO}_{4}$. The pellet from recentrifugation $(38000 \mathrm{~g}, 20 \mathrm{~min})$ was weighed and resuspended in $40 \mathrm{~mm}$-potassium phosphate buffer, $\mathrm{pH} 7 \cdot 7$, plus $2 \mathrm{mM}-\mathrm{MgCl}_{2}$. The cells were stored on ice and used within $24 \mathrm{~h}$.

Incubation with ${ }^{13} \mathrm{C}$-labelled compounds. $\left[{ }^{13} \mathrm{C}\right]$ methanol and $\left[{ }^{13} \mathrm{C}\right]$ formaldehyde were both $99 \%$ enrichments from Amersham, the latter being purchased as a $25 \%(\mathrm{w} / \mathrm{w})$ aqueous solution. The medium was as for resuspension of cells. Short-term incubations were done in an $\mathrm{O}_{2}$ electrode chamber. Longer experiments used conical flasks, incubated with shaking at $30^{\circ} \mathrm{C}$. The incubations were terminated by centrifugation to remove the cells $(12000 \mathrm{~g}$, $5 \mathrm{~min}$ ), and the supernatants stored at $0{ }^{\circ} \mathrm{C}$ in stoppered glass vials. NMR spectra were run within $36 \mathrm{~h}$ of the start of the experiment.

Detection of ${ }^{13} C$ distribution by $N M R . \mathrm{D}_{2} \mathrm{O}(20 \%, \mathrm{v} / \mathrm{v})$ was added to the supernatants to provide a lock signal. ${ }^{13} \mathrm{C}$ spectra at $50 \cdot 1 \mathrm{MHz}$ were obtained with a JEOL FX-200 Fourier transform spectrometer, using $10 \mathrm{~mm}$ diameter tubes and ambient temperature. Transients (2000-5400) over a $12547 \mathrm{~Hz}$ sweep width were collected into 16000 data points. A relaxation delay of $0.2 \mathrm{~s}$ was inserted between each pulse. Chemical shifts $(\delta)$ were measured relative to tetramethylsilane.

Oxygen electrode experiments. A Clark type $\mathrm{O}_{2}$ electrode (Hansatech) was connected to a pen chart recorder. The medium was as for resuspension of cells, unless otherwise stated.

Quantitative determination of methanol and formaldehyde. Methanol was determined by gas-liquid chromatography (Hyman \& Wood, 1983). Formaldehyde was assayed as described by Chrastil \& Wilson (1975).

Measurement of $\mathrm{NH}_{4}^{+}$utilization. An $\mathrm{NH}_{4}^{+}$selective electrode and reference electrode were used (Hyman \& Wood, 1983). The electrode potential was monitored as $\mathrm{NH}_{4}^{+}$oxidation progressed, until the suspension had become anaerobic. The potential was then titrated back to its original value by additions from standard solutions of $\mathrm{NH}_{4}^{+}$. KCN (1 mM) was then added to prevent further metabolism.

Chemicals. Acetylene (commercial grade) was passed through a $10 \%(\mathrm{w} / \mathrm{v})$ solution of $\mathrm{CuSO}_{4} \cdot 5 \mathrm{H}_{2} \mathrm{O}(\mathrm{Hyman} \&$ Wood, 1985). Formaldehyde solutions were prepared at about $100 \mathrm{~mm}$ by heating water plus an appropriate quantity of paraformaldehyde in an autoclave at $115^{\circ} \mathrm{C}$ for $30 \mathrm{~min}$ (Hunter et al., 1984).

\section{RESULTS AND DISCUSSION}

\section{Methanol conversion to formaldehyde and formate}

Incubation of $N$. europaea with $\left[{ }^{13} \mathrm{C}\right]$ methanol led to progressive disappearance of the ${ }^{13} \mathrm{C}$ NMR signal for methanol, at a chemical shift of $\delta=49 \cdot 2$ (p.p.m.). A signal at $\delta=82 \cdot 1$, attributable to formaldehyde (Hunter et al., 1984), rose for some hours but became weaker at long incubation times, while a signal at $\delta=171 \cdot 2$, attributable to formate (Hunter et al., 1984), showed a more gradual rise (Fig. 1). No methanol oxidation occurred in the absence of cells.It should be noted that signal intensities for different metabolites are not directly comparable, because some compounds relax more then others between pulses, as the spectra are being compiled (Levy et al., 1980).

A signal at $\delta=163.4$ corresponding to $\left[{ }^{13} \mathrm{C}\right]$ bicarbonate (Hunter et al., 1984) was only observed on one occasion. This can be contrasted with the clear evidence for ${ }^{14} \mathrm{CO}_{2}$ formation from ${ }^{14} \mathrm{CH}_{4}$ in the experiments of Jones \& Morita (1983). They generally obtained only a low 


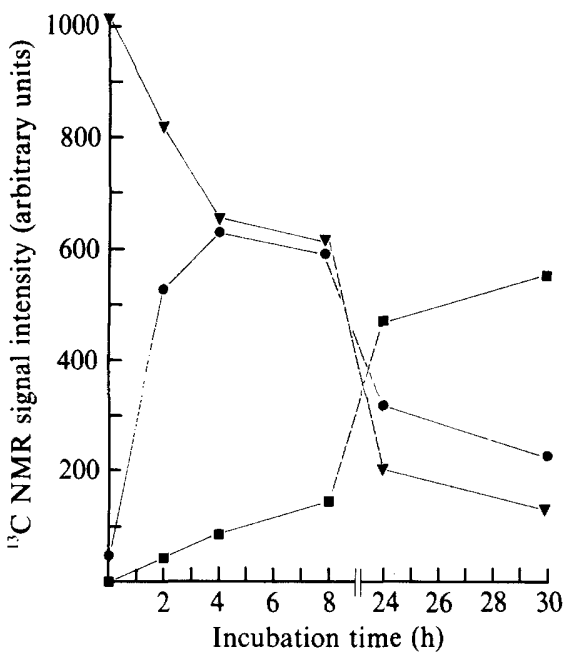

Fig. 1

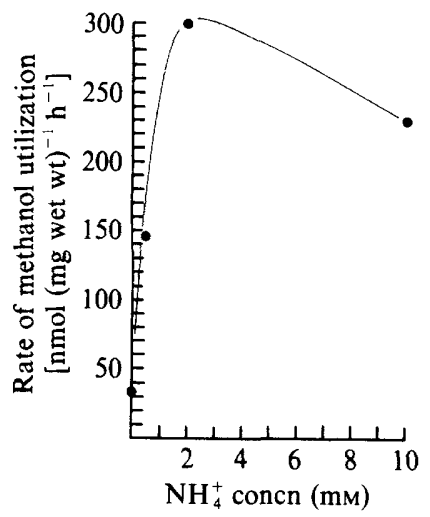

Fig. 2

Fig. $1 .{ }^{13} \mathrm{C}$ NMR signal intensities for supernatants from incubation of $N$. europaea with $10 \mathrm{mM}-$ $\left[{ }^{13} \mathrm{C}\right]$ methanol and $10 \mathrm{~mm}-\mathrm{NH}_{4}^{+}$. The cell density was $6 \mathrm{mg}$ wet $\mathrm{wt} \mathrm{ml}^{-1}$. The cells were incubated with the reagents on an orbital shaker at $30^{\circ} \mathrm{C}$. At intervals samples were taken and the cells removed by centrifugation. The ordinate shows the ${ }^{13} \mathrm{C}$ NMR signal intensities at chemical shifts appropriate for methanol $(\boldsymbol{\nabla})$, formaldehyde $(\boldsymbol{O})$ and formate $(\boldsymbol{\square})$.

Fig. 2. Effect of $\mathrm{NH}_{4}^{+}$on the rate of methanol oxidation. Methanol $(0.37 \mathrm{mM})$ and $\mathrm{NH}_{4} \mathrm{Cl}$ as required were added to $10 \mathrm{~mm}$-sodium phosphate, $\mathrm{pH} 7 \cdot 1$, in an oxygen electrode chamber. Washed cells were then added to give 0.5 to $10 \mathrm{mg}$ wet $\mathrm{wt} \mathrm{ml}^{-1}$ as appropriate. The time taken for the system to become anaerobic was monitored. The remaining methanol was then determined by GLC.

\section{Table 1. Inhibition of methanol oxidation}

Each experiment used $0.18 \mathrm{~g}$ wet wt of washed cells in $2.5 \mathrm{ml}$ of medium. For inhibition by allylthiourea the cells were equilibrated with the inhibitor for $10 \mathrm{~min}$ before addition of methanol. For inhibition by acetylene the gas was gently bubbled through the suspension for $5 \mathrm{~min}$, followed by shaking to restore aeration. Each incubation was with $\left.10 \mathrm{mM}-{ }^{13} \mathrm{C}\right] \mathrm{methanol}$ for $30 \mathrm{~min}$. The cells were then removed by centrifugation.

Incubation conditions

No cells

No inhibitor $20 \mu \mathrm{M}$-allylthiourea

Acetylene treated
${ }^{13} \mathrm{C}$ NMR signal intensity (arbitrary units)

$\begin{array}{ccc}\text { Methanol } & \text { Formaldehyde } & \text { Formate } \\ 938 & <10 & <10 \\ 660 & 365 & 181 \\ 939 & <10 & <10 \\ 1036 & <10 & <10\end{array}$

percentage conversion, which would be difficult to detect by NMR. In our experiments $\left[{ }^{13} \mathrm{C}\right]$ bicarbonate could easily have been lost to the atmosphere as ${ }^{13} \mathrm{CO}_{2}$. However, the steadily rising formate signal during the $30 \mathrm{~h}$ incubation shown in Fig. 1 implies that formate was only slowly oxidized.

\section{Inhibition of methanol oxidation}

Ammonia monooxygenase has several characteristic inhibitors. It is irreversibly inhibited by acetylene, which acts as a suicide substrate (Hyman \& Wood, 1985). Allylthiourea is a potent reversible inhibitor (Hooper \& Terry, 1973). Allylthiourea, or prior exposure to acetylene, both prevented methanol oxidation, monitored by NMR (Table 1) or by quantitative assay.

\section{Effect of reductant and $\mathrm{NH}_{4}^{+}$on methanol oxidation}

Hydrazine is an alternative substrate for hydroxylamine oxidoreductase in $N$. europaea (Nicholas \& Jones, 1960). It is a convenient reductant in studies of organic conversions by the 
monooxygenase, because higher rates are obtained than with hydroxylamine (Hyman \& Wood, 1984). With hydrazine as reductant the rate of $\mathrm{O}_{2}$ uptake was approximately doubled on addition of methanol, the stimulation being reversed by allylthiourea (results not shown). This behaviour is characteristic of substrates for ammonia monooxygenase (Hyman \& Wood, 1983, 1984). It is explained by electrons passing preferentially to the monooxygenase, which consumes $1 \mathrm{O}_{2}$ per $2 e^{-}$. When the monooxygenase is unable to turn over, because of inhibition or lack of substrate, electrons pass to the terminal oxidase, which only reduces $1 \mathrm{O}_{2}$ per $4 e^{-}$.

The effect of $\mathrm{NH}_{4}^{+}$on the rate of methanol oxidation was studied by GLC (Fig. 2). A stimulatory effect of low $\mathrm{NH}_{4}^{+}$concentrations has been observed with several substrates for the monooxygenase. It is explained by an increased supply of reductant; if hydroxylamine is present at a steady-state concentration, each oxidation of ammonia to nitrite leaves two electrons available for an organic oxidation (Hyman \& Wood, 1983; Wood, 1986). The inhibitory effect of high $\mathrm{NH}_{4}^{+}$concentrations has been observed with other organic substrates (Hyman \& Wood, $1983,1984)$. It is explained by competition between the organic substrate and ammonia for a common active site. Jones \& Morita (1983) obtained a similar profile for methane oxidation as a function of $\mathrm{NH}_{4}^{+}$concentration.

\section{How specific is ammonia monooxygenase?}

The experiments described above show that methanol oxidation was inhibited by characteristic inhibitors of ammonia monooxygenase, which would not have affected a conventional methanol dehydrogenase. The effect of hydrazine and $\mathrm{NH}_{4}^{+}$was as found for other organic conversions by ammonia monooxygenase. One may conclude that the range of substrates for the monooxygenase includes methanol.

The specificity of an enzyme for different substrates can be determined by measuring relative values for the parameter $k_{\text {cat }} / K_{\mathrm{m}}$. If two substrates at concentrations $[A]$ and $[B]$ are simultaneously converted by the enzyme at rates $v_{A}$ and $v_{B}$, then

$$
\left(k_{\text {cat }} / K_{\mathrm{m}}\right)_{A} /\left(k_{\text {cat }} / K_{\mathrm{m}}\right)_{B}=\left(v_{A} / v_{B}\right) .([B] /[A])
$$

(see Cornish-Bowden, 1979). Such measurements are most accurate when similar proportions of the two substrates are converted in a given time; a $\mathrm{pH}$ of $7 \cdot 1$ was found to be appropriate. At this $\mathrm{pH}$, methanol gave a $\left(k_{\text {cat }} / K_{\mathrm{m}}\right)$ of $0.77 \pm 0 \cdot 1$ (from six determinations), relative to unity for $\mathrm{NH}_{4}^{+}$. However, the true physiological substrate for the monooxygenase is uncharged $\mathrm{NH}_{3}$, not $\mathrm{NH}_{4}^{+}$ (Suzuki et al., 1974). At $30^{\circ} \mathrm{C}$ the $\mathrm{pK}$ for deprotonation of $\mathrm{NH}_{4}^{+}$is $9 \cdot 1$ (Sillén \& Martell, 1964). Thus, at $\mathrm{pH} 7 \cdot 1$ only about $1 \%$ would be uncharged $\mathrm{NH}_{3}$. If the $k_{\text {cat }} / \mathrm{K}_{\mathrm{m}}$ for methanol is reevaluated relative to unity for $\mathrm{NH}_{3}$, a value of only 0.008 is obtained. The enzyme is therefore more specific than the experiment would suggest. An earlier study found methane to be a slightly poorer substrate, $k_{\text {cat }} / K_{\mathrm{m}}$ being 0.004, relative to unity for $\mathrm{NH}_{3}$ (Hyman \& Wood, 1984).

\section{Attempts to detect growth of $N$. europaea on methanol}

No convincing evidence for increase in cell protein as a result of methanol utilization could be obtained.

\section{Comparative effects of methanol and formaldehyde on cell cultures}

The effect of adding methanol or formaldehyde to cells in shake-flask culture, shortly after the start of exponential growth, is shown in Figs 3 and 4. Both reagents invariably slowed down the rate of nitrite production. Formaldehyde was a much more potent inhibitor than methanol; cultures treated with $1 \mathrm{~mm}$-formaldehyde were apparently killed, while $5 \mathrm{~mm}$-methanol had less effect than $0.1 \mathrm{~mm}$-formaldehyde. Formaldehyde toxicity thus plays an important part in determining the response of $N$. europaea to methanol.

\section{Is formaldoxime responsible for the inhibitory effects of formaldehyde?}

Ammonia oxidation to nitrate involves the production of hydroxylamine as an intermediate (Hofman \& Lees, 1953). Formaldehyde reacts readily with hydroxylamine, forming formaldoxime.

$$
\mathrm{H}_{2} \mathrm{C}(\mathrm{OH})_{2}+\mathrm{H}_{2} \mathrm{NOH} \rightleftharpoons \mathrm{H}_{2} \mathrm{C}=\mathrm{NOH}+2 \mathrm{H}_{2} \mathrm{O}
$$




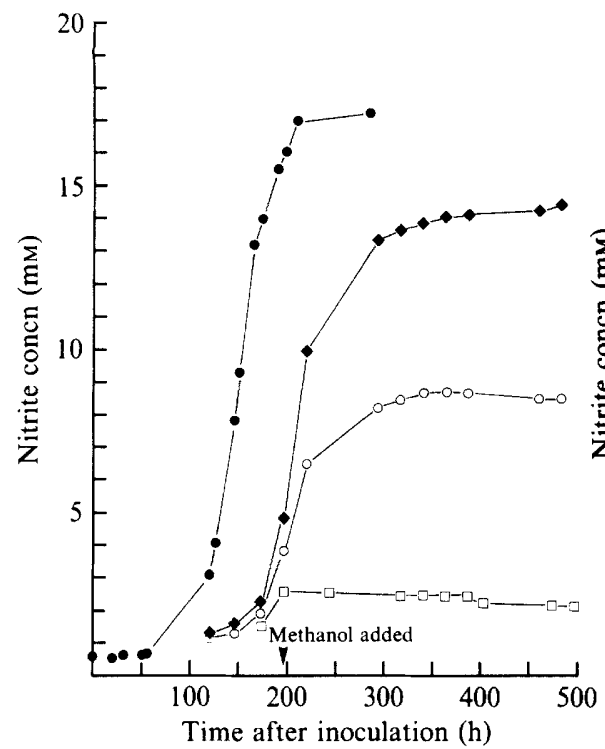

Fig. 3

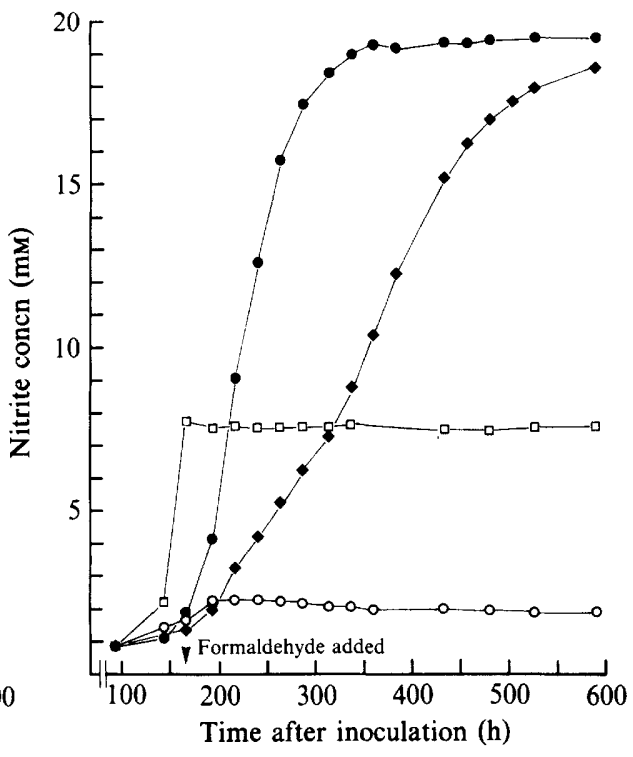

Fig. 4

Fig. 3. Effect of methanol on nitrite production by cultures of $N$. europaea. Four shake-flasks were inoculated with $N$. europaea, and nitrite concentrations were monitored as a function of time. In early exponential phase one flask was left untreated $(\mathcal{O})$, while the other three received an addition of $1(\diamond), 5$ (O) or $100(\square)$ mM-methanol.

Fig. 4. Effect of formaldehyde on nitrite production by cultures of $N$. europaea. Four shake-flasks were inoculated and monitored as in Fig. 3. In early exponential phase one flask was left untreated ( $\odot$ ), while the other three received an addition of $0.1(\diamond), 1(O)$ or $10(\square) \mathrm{mm}$-formaldehyde.

This was verified by ${ }^{13} \mathrm{C}$ NMR. The NMR spectrum obtained from $1 \mathrm{~mm}-\left[{ }^{13} \mathrm{C}\right]$ formaldehyde showed a signal at $\delta=82 \cdot 1$, attributable to hydrated formaldehyde, plus a minor signal at $\delta=$ 62.8. Formaldehyde solutions contain self-addition compounds in equilibrium with the monomer (Dankelman \& Daemen, 1976); the minor signal was at a chemical shift appropriate for the dimer, $\mathrm{HOCH}_{2} \mathrm{OCH}_{2} \mathrm{OH}$. On addition of equimolar hydroxylamine the signal from hydrated formaldehyde disappeared, being replaced by a signal at $\delta=140 \cdot 6$. This is close to the chemical shift reported for formaldoxime (Lichter et al., 1974).

Additions of formaldoxime inhibited the overall process of ammonia oxidation to a much greater extent than the same concentration of formaldehyde (Fig. 5). In the experiment shown in Fig. 6 hydroxylamine was added to cells plus formaldehyde. The rate of $\mathrm{O}_{2}$ uptake became progessively inhibited, as the hydroxylamine was converted into formaldoxime. Within a few minutes inhibition was almost complete. Further additions of hydroxylamine were then made. With an excess of hydroxylamine over formaldehyde the rate of $\mathrm{O}_{2}$ uptake was still much slower than for normal hydroxylamine oxidation. It is clear that formaldoxime has an inhibitory effect on hydroxylamine oxidation.

Incubation of $N$. europaea with $\left[{ }^{13} \mathrm{C}\right]$ formaldoxime led to production of $\left[{ }^{13} \mathrm{C}\right]$ formate, which became the only detectable compound in ${ }^{13} \mathrm{C}$ NMR spectra for the cell supernatant. The oxidation was not inhibited by allylthiourea, implying that the monooxygenase was not responsible. An alternative substrate for hydroxylamine oxidoreductase, $N$-methylhydroxylamine $\left(\mathrm{CH}_{3} \mathrm{NHOH}\right)$, has structural similarities with formaldoxime (Ritchie \& Nicholas, 1974; Hooper \& Terry, 1977). It is therefore plausible that formaldoxime is slowly oxidized by hydroxylamine oxidoreductase, as well as being an inhibitor of hydroxylamine oxidation.

Reaction (1) is reversible; its consequences will depend on the relative concentrations of the different species present at equilibrium. An equilibrium constant, $K=4 \times 10^{4} \mathrm{M}^{-1}$, can be 


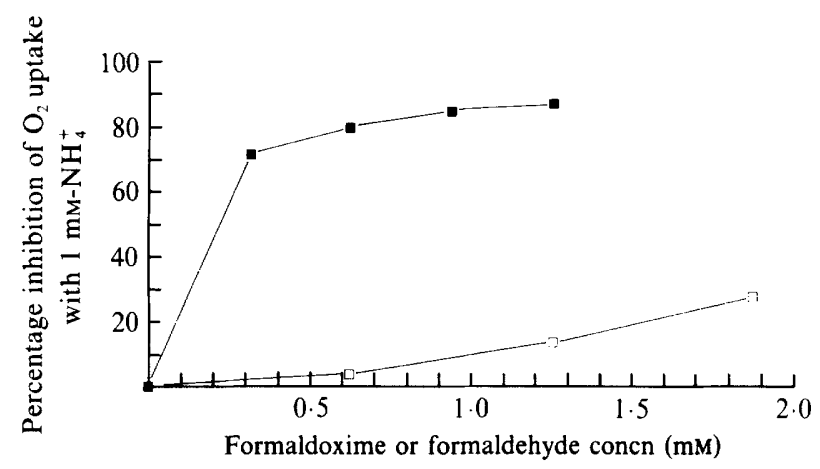

Fig. 5. Comparison of formaldehyde and formaldoxime as inhibitors of ammonia oxidation. Washed cells were added to medium in an oxygen electrode chamber to give $0.5 \mathrm{mg}$ wet wt $\mathrm{ml}^{-1}$. $\mathrm{NH}_{4}^{+}$was added to $1 \mathrm{~mm}$. Formaldehyde ( $\square$ ) was added from a $50 \mathrm{~mm}$ solution in water. Formaldoxime ( $\square$ ) was added from a solution made up as $50 \mathrm{~mm}$-formaldehyde plus $25 \mathrm{~mm}$-hydroxylamine, assumed to contain $25 \mathrm{~mm}$-formaldoxime plus excess formaldehyde.

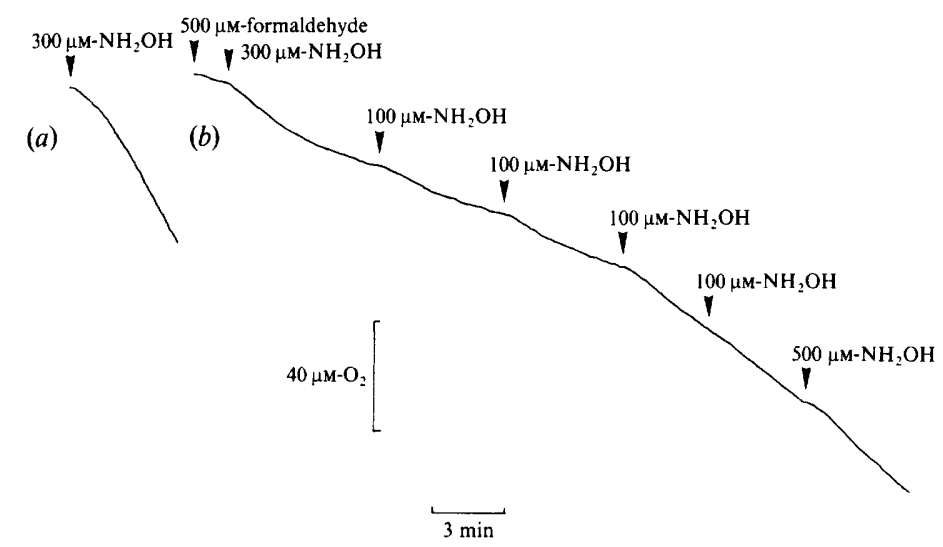

Fig. 6. Effect of formaldehyde on $\mathrm{O}_{2}$ uptake with hydroxylamine as reductant. Washed cells were added to medium in an oxygen electrode chamber to give $0.3 \mathrm{mg}$ wet wt $\mathrm{ml}^{-1}$. In experiment $(a), 0.3 \mathrm{mM}^{-}$ hydroxylamine was added as shown. In experiment $(b), 0.5 \mathrm{~mm}$-formaldehyde was added, followed by $0.3 \mathrm{~mm}$-hydroxylamine. Further $0.1 \mathrm{~mm}$ additions of hydroxylamine were made as shown.

deduced from measurements of Sander \& Jencks (1968), who found $K=6 \cdot 1 \times 10^{3} \mathrm{M}^{-1}$ for the semicarbazide adduct of formaldehyde, while other aldehydes gave an equilibrium constant for oxime formation about six times that for the semicarbazide adduct. If reaction (1) approaches equilibrium,

$$
\text { [formaldoxime]/[hydroxylamine }]=K \times[\text { formaldehyde }]
$$

Since $K=4 \times 10^{4} \mathrm{M}^{-1}$, it follows that the concentration of formaldoxime will be greater than that of hydroxylamine when the formaldehyde concentration is in excess of $25 \mu \mathrm{M}$. By incubating $N$. europaea with methanol and ammonia we have obtained formaldehyde concentrations of $2 \mathrm{mM}$, giving a predicted ratio[formaldoxime]:[hydroxylamine] of 80 . Exactly how much difference this will make cannot be assessed, since the steady-state concentration of hydroxylamine during ammonia oxidation is too low to be detected (Wood, 1986), and we have no direct evidence for its conversion to formaldoxime.

Why is $N$. europaea unable to profit from methanol oxidation?

In conventional methylotrophs, methanol oxidation is mediated by methanol dehydrogenase, with pyrroloquinolinequinone (PQQ) as its prosthetic group. We have treated $N$. europaea 
according to standard procedures for extracting PQQ (Duine \& Frank, 1980; Ameyama et al., 1981), but have failed to detect its characteristic fluorescence in the extact (Dekker et al., 1982). The inhibition of methanol oxidation by acetylene treatment or allylthiourea is consistent with an absence of methanol dehydrogenase.

Methanol oxidation is therefore a consequence of the lack of specificity of ammonia monooxygenase. The conversion of methanol to formaldehyde will have a debilitating effect, because it consumes valuable reductant. Nevertheless, it could have useful consequences, if the cells were equipped with appropriate enzymes. Addition of formaldehyde or formate to resting cells in an $\mathrm{O}_{2}$ electrode chamber resulted in no significant stimulation of the $\mathrm{O}_{2}$ uptake rate (data not shown). The detectability of formaldehyde and formate in ${ }^{13} \mathrm{C}$ NMR spectra is further evidence against significant activity of formaldehyde or formate dehydrogenases. The reason why $N$. europaea seems unable to use reduced $\mathrm{C}_{1}$ compounds as fuels may be the same as why the cells are unable to grow heterotrophically by oxidation of larger carbon compounds. The ability to use ammonia oxidation as an energy source implies a delicate balance between three competing electron sinks - the monooxygenase, the terminal oxidase, and $\mathrm{NAD}^{+}$reduction by reversed electron flow. Underlying control mechanisms may be incompatible with any alternative mode of respiration (Wood, 1987).

It is estimated that $\mathrm{CO}_{2}$ fixation by the Calvin cycle consumes about $80 \%$ of the energy budget of an autotroph (Forrest \& Walker, 1971; Kelly, 1978). Since formaldehyde contains carbon at the same level of reduction as in carbohydrate, one might hope that an appropriate design of experiment would reveal enhanced growth on addition of methanol. However, in our studies we have been unable to show any beneficial consequences of methanol oxidation. The results shown in Fig. 4 suggest that the harmful effects lie in the uncontrolled production of formaldehyde. There may be analogies with the very low tolerance of certain methanotrophs to free methanol (Whittenbury et al., 1970). However, a specific mechanism for sensitivity to formaldehyde is provided by the inhibitory action of formaldoxime on hydroxylamine oxidation.

We are grateful to Dr M. Murray for the NMR spectra, and to the SERC for research support.

\section{REFERENCES}

Ameyama, M., Matsushita, K., Ohno, Y., ShinAGAWA, E. \& ADACHI, O. (1981). Existence of a novel prosthetic group, $\mathrm{PQQ}$, in membrane-bound, electron transport chain-linked, primary dehydrogenases of oxidative bacteria. FEBS Letters 130, 179183.

Chrastil, J. \& Wilson, J. T. (1975). A sensitive colorimetric method for formaldehyde. Analytical Biochemistry 63, 202-207.

CORnish, A., Nicholls, K. M., Scott, D., Hunter, B. K., Aston, W. J., Higgins, I. J. \& SANDERS, J. K. M. (1984). In vivo ${ }^{13} \mathrm{C} N \mathrm{NMR}$ investigations of methanol oxidation by the obligate methanotroph Methylosinus trichosporium OB3b. Journal of General Microbiology 130, 2565-2575.

CORNISH-BOWDEN, A. (1979). Fundamentals of Enzyme Kinetics, p. 85. London: Butterworths.

Dankelman, W. \& Daemen, J. M. H. (1976). Gas chromatographic and nuclear magnetic resonance determination of linear formaldehyde oligomers in formalin. Analytical Chemistry 48, 401-404.

DekKer, R. H., Duine, J. A., Frank, J., Verwiel, P. E. J. \& Westerling, J. (1982). Covalent addition of $\mathrm{H}_{2} \mathrm{O}$, enzyme substrates and activators to pyrroloquinoline quinone, the coenzyme of quinoproteins. European Journal of Biochemistry 125, 69-73.

DROZD, J. W. (1976). Energy coupling and respiration in Nitrosomonas europaea. Archives of Microbiology 110, 257-262.
DrozD, J. W. (1980). Respiration in the ammonia oxidizing chemoautotrophic bacteria. In Diversity of Bacterial Respiratory Systems, vol. 2, pp. 87-111. Edited by C. J. Knowles. Boca Raton, Florida : CRC Press.

DuINE, J. A. \& Frank, J. (1980). The prosthetic group of methanol dehydrogenase. Biochemical Journal 187, 221-226.

ForRest, W. W. \& Walker, D. J. (1971). The generation and utilization of energy during growth. Advances in Microbial Physiology 5, 213-274.

Hofman, T. \& LEEs, H. (1953). The biochemistry of the nitrifying organisms. Biochemical Journal 54, 579583.

HOOPER, A. B. \& TERRY, K. R. (1973). Specific inhibitors of ammonia oxidation in Nitrosomonas. Journal of Bacteriology 115, 480-485.

HoOPER, A. B. \& TERRY, K. R. (1977). Hydroxylamine oxidoreductase from Nitrosomonas: inactivation by hydrogen peroxide. Biochemistry 16, 455-459.

Hunter, B. K., Nicholls, K. M. \& SANDERS, J. K. M. (1984). Formaldehyde metabolism by Escherichia coli. In vivo carbon, deuterium and two-dimensional NMR observations of multiple detoxifying pathways. Biochemistry 23, 508-514.

Hyman, M. R. \& Wood, P. M. (1983). Methane oxidation by Nitrosomonas europaea. Biochemical Journal 212, 31-37.

HymaN, M. R. \& WoOD, P. M. (1984). Ethylene 
oxidation by Nitrosomonas europaea. Archives of Microbiology 137, 155-158.

Hyman, M. R. \& Wood, P. M. (1985). Suicidal inactivation and labelling of ammonia monooxygenase by acetylene. Biochemical Journal 227, 719-725.

Hyman, M. R., Samsome-Smith, A. W., Shears, J. H. \& WoOD, P. M. (1985). A kinetic study of benzene oxidation to phenol by whole cells of Nitrosomonas europaea and evidence for the further oxidation of phenol to hydroquinone. Archives of Microbiology 143, 302-306.

JoNES, R. D. \& MORITA, R. Y. (1983). Methane oxidation by Nitrosococcus oceanus and Nitrosomonas europaea. Applied and Environmental Microbiology 45, 401-410.

KELLY, D. P. (1978). Bioenergetics of chemolithotrophic bacteria. In Companion to Microbiology, pp. 363-386. Edited by A. T. Bull \& P. M. Meadow. London: Longman.

KrÜMmel, A. \& HaRMS, H. (1982). Effect of organic matter on growth and cell yield of ammoniaoxidizing bacteria. Archives of Microbiology 133, 5054.

Levy, G. C., Lichter, R. L. \& Nelson, G. L. (1980). Carbon-13 Nuclear Magnetic Resonance Spectroscopy, 2nd edn. New York: John Wiley.

Lichter, R. L., Dorman, D. E. \& Wasylishu, R. (1974). Geometrical dependences of carbon-nitrogen coupling constants. Oximes. Journal of the American Chemical Society 96, 930-932.

MARTINY, H. \& KoOPS, H. P. (1982). Incorporation of organic compounds into cell protein by lithotrophic, ammonia-oxidizing bacteria. Antonie van Leeuwenhoek 48, 327-336.

Nicholas, D. J. D. \& Jones, O. T. G. (1960). Oxidation of hydroxylamine in cell-free extracts of Nitrosomonas europaea. Nature, London 185, 512514.
Ritchie, G. A. F. \& Nicholas, D. J. D. (1974). The partial characterization of purified nitrite reductase and hydroxylamine oxidase from Nitrosomonas europaea. Biochemical Journal 138, 471-480.

SANDER, E. G. \& Jencks, W. P. (1968). Equilibria for additions to the carbonyl group. Journal of the American Chemical Society 90, 6154-6162.

Shears, J. H. \& Wood, P. M. (1986). Tri- and tetramethylhydroquinone as electron donors for ammonia monooxygenase in whole cells of Nitrosomonas europaea. FEMS Microbiology Letters 33, 281284.

Sillén, L. G. \& Martell, A. E. (Editors) (1964). Stability Constants of Metal-Ion Complexes. Chemical Society Special Publication no. 17, p. 159. London: The Chemical Society.

STRICKLER, C. J. \& KaSHA, M. (1963). Solvent effects on the electronic absorption spectrum of nitrite ion. Journal of the American Chemical Society 85, 28992901.

Suzuki, I., Dular, U. \& Kwok, S. C. (1974). Ammonia or ammonium ions as substrate for oxidation by Nitrosomonas europaea cells and extracts. Journal of Bacteriology 120, 556-558.

TsanG, D. C. Y. \& Suzuki, I. (1982). Cytochrome $c$ 554 as a possible donor in the hydroxylation of ammonia and carbon monoxide in Nitrosomonas europaea. Canadian Journal of Biochemistry 60, 10181024.

Whittenbury, R., Phillips, K. C. \& Wilkinson, J. F. (1970). Enrichment, isolation and some properties of methane-utilizing bacteria. Journal of General Microbiology 61, 205-218.

Wood, P. M. (1987). Nitrification as a bacterial energy source. In Nitrification. Edited by J. Prosser. Society for General Microbiology Special Publication (in the Press). 